\title{
Neurologic Assessment of the Neurocritical Care Patient: The Neurologic Wake-Up Test
}

\author{
Shane Musick $\mathrm{MD}^{1^{*}}$, Anthony Alberico $\mathrm{MD}^{1}$ \\ ${ }^{1}$ Department of Neurosurgery, Marshall University, Joan C. Edwards School of Medicine, \\ Huntington, West Virginia, USA \\ Correspondence: \\ Shane Musick MD \\ Musick22@marshall.edu
}

Keywords: neurological wake-up test, multimodality monitoring, neurologic examination, daily-interruption of sedation, traumatic brain injury, sedation cessation

\begin{abstract}
Sedation is a ubiquitous practice in ICUs and NCCUs. It has the benefit of reducing cerebral energy demands, but also precludes an accurate neurologic assessment. Because of this, sedation is intermittently stopped for the purposes of a neurologic assessment, which is termed a neurologic wake-up test (NWT). NWTs are considered to be the gold-standard in continued assessment of brain-injured patients under sedation. NWTs also produce an acute stress response that is accompanied by elevations in blood pressure, respiratory rate, heart rate, and ICP. Utilization of cerebral microdialysis and brain tissue oxygen monitoring indicates that this is not mirrored by alterations in overall cerebral metabolism, and seldom affects oxygenation. The hard contraindications for the NWT are preexisting intracranial hypertension, barbiturate treatment, status epilepticus, and hyperthermia. However, hemodynamic instability, sedative use for primary ICP control, and sedative use for severe agitation or respiratory distress are considered significant safety concerns. Despite ubiquitous recommendation, it is not clear if additional clinically relevant information is gleaned through its use, especially with the contemporaneous utilization of multimodality monitoring. Various monitoring modalities provide unique and pertinent information about neurologic function, however, their role in improving patient outcomes and guiding treatment plans has not been fully elucidated. There is a paucity of information pertaining to the optimal frequency of NWTs, and if it differs based on type of injury. Only one concrete recommendation was found in the literature, exemplifying the uncertainty surrounding its utility. The most common sedative used and recommended is propofol because of its rapid onset, short duration, and reduction of cerebral energy requirements. Dexmedetomidine may be employed to facilitate serial NWTs, and should always be used in the non-intubated patient or if propofol infusion syndrome (PRIS) develops. Midazolam is not recommended due to tissue accumulation and residual sedation confounding a reliable NWT. Thus, NWTs are well tolerated in most patients and remain recommended as the gold-standard for continued neuromonitoring. Predicated upon one expert panel, they should be performed at least one time per day. Propofol or dexmedetomidine are the main sedative choices, both enabling a rapid awakening and consistent NWT.
\end{abstract}

\section{Introduction}


The Neurologic Wake-Up Test

There is widespread use of sedation for patients in the intensive care unit (ICU) and neurocritical care unit (NCCU). This is a necessary practice to facilitate endotracheal intubation and mechanical ventilation, however, it is also Janus-faced. There is good clinical utility, such as controlling patient distress, attenuating anxiety, and abating pain recognition (1), with neurospecific benefits including reduced metabolic demands to decrease energy consumption (2), decreased stress-related injury, as well as seizure, temperature, and intracranial pressure (ICP) control $(3,4)$. However, over sedation harbors complications, including increased morbidity (5, 6), prolonged ventilation with associated pneumonia (3), greater muscular atrophy, venous stasis, thrombosis, and a protracted ICU length of stay. Further, it may increase hospital costs secondary to ordering unnecessary neuroimaging (1). Too little sedation can magnify agitation and autonomic instability, leading to elevated ICP, hypertension, tachycardia, and cerebral oxygen consumption (1). Thus, risks and benefits must be carefully weighed when it comes to achieving optimal sedation.

Sedation also precludes an accurate neurologic examination, and continued sedation may mask significant changes in the patient's neurologic condition (7). This is concerning, as upwards of $40 \%$ of patients with a traumatic brain injury (TBI) demonstrate a significant deterioration of neurologic function during the first 48 hours $(3,8)$. There is a known secondary deterioration that evolves during the early period of brain injury that is heterogenous and hard to predict (9). This is due to secondary injury cascades that activate inflammatory, excitotoxic, metabolic, and vascular phenomena. This augments oxidative stress, elevates ICP and metabolic demands, causes cerebral edema, activates coagulation cascades, and impairs regional blood flow (7). Continued sedation can also prevent the acquisition of an accurate Glasgow coma scale (GCS) score. This is imperative, as GCS scores are a robust prognostic marker and indicator of potential surgical intervention $(10,11)$, and are highly predictive of 6-month outcomes in TBI patients (12). This underlies the necessity for a brief cessation of sedation for an accurate neurologic assessment, termed the neurological wake-up test (NWT). The NWT is considered to be the gold-standard for neuro-monitoring $(1,3)$, and is the basis for neuroanatomical localization of pathology, identifying undiagnosed neurologic ailments, detecting early neurologic signs of insult, determining prognosis, and guiding appropriate therapy $(3,7,13)$.

Serial NWTs are an integral part of continued ICU and NCCU assessment of neurologic functioning but are concerning because they require a temporary cessation of sedation. This results in a significant sympathetic nervous system (SNS) discharge, potentially resulting in neurologic injury via elevating ICP, increasing cerebral oxygen demand, and reducing cerebral perfusion. However, this must be weighed against the additional clinical information acquired. Moreover, with the increasing utilization of multimodality monitoring, there may be enough information gathered to make the NWT both harmful and redundant. Therefore, this paper will aim to elucidate the utility of the NWT, if it still has a role with multimodality monitoring, if there is an optimal frequency that imparts the most favorable risk to benefit profile, and if the choice of sedative has an influence on these quandaries. For this review, PubMed was searched for all existing literature using the terms brain injury, head injury, or TBI, with the terms sedation cessation, daily interruption of sedation, wake-up test, stopping sedation, spontaneous awakening trial, neurologic examination, multimodality monitoring, frequency of awakening, and/or frequency of neurologic exam. 
The Neurologic Wake-Up Test

\section{Multimodality Monitoring}

The brain is known to be the most metabolically active organ in the body by weight, with a cerebral metabolic demand for $\mathrm{O}_{2}\left(\mathrm{CMRO}_{2}\right)$ between 3-3.5 $\mathrm{ml} \mathrm{O}_{2} / 100 \mathrm{~g} / \mathrm{min}$, which is roughly $15-20 \%$ of total cardiac output. To maintain this high demand for cerebral blood flow (CBF), adequate cerebral perfusion pressure (CPP) is required, defined as the difference between mean arterial pressure (MAP) and ICP. In a healthy brain, there is robust autoregulatory mechanisms to maintain constant CBF across a range of MAPs from 65-150 mmHg. However, in the presence of neurologic insult, there is often either regional or global impairment of autoregulation (1). Thus, continued monitoring of ICP and CPP are often necessary. Utilizing transcranial doppler (TCD) may also assist in assessing the degree of autoregulation failure (14). Other monitoring modalities include brain tissue oxygen tension monitoring $\left(\mathrm{PbtiO}_{2}\right)$, jugular venous oxygen saturation $\left(\mathrm{SjvO}_{2}\right)$, and brain neurochemistry by intracerebral microdialysis (MD). Newer, less invasive monitoring technologies including optic ultrasound, and the automated pupillometer to directly augment the NWT are also seeing increased use.

$\underline{\text { ICP }}$

Normal ICP values are between 5-15 mmHg (15), with a generally accepted normal value of $<20 \mathrm{mmHg}$. Increased ICP is defined as pressures greater than $20 \mathrm{mmHg}$ for more than 5 minutes. This monitoring is typically performed via insertion of a catheter into the lateral ventricle, acting as an external ventricular drain (EVD), which concomitantly allows for cerebrospinal fluid (CSF) drainage for ICP control if required (7). ICP monitoring is recommended as part of the official TBI guidelines (16); consequently, there is widespread use of ICP monitoring of brain injured patients across NCCUs $(7,9,17)$. The Brain Trauma Foundation recommends monitoring for comatose patients (GCS of 3-8) that have an abnormal CT scan (18). Those with the highest risk of developing intracranial hypertension following head injury are severely head injured comatose patients (GCS $<8$ ), with very few patients with mild to moderate head injury showing secondary deterioration (18).

Increased ICP is a recognized cause of morbidity and especially mortality after TBI (7, 12, 18-20). Mechanistically, elevated ICP can acutely cause ischemia by directly reducing CBF. ICP is frequently elevated following neurologic insult, compounded by a failure of CBF autoregulation, which exacerbates the problem (9). There is evidence to suggest that aggressive management of elevated ICP can improve outcomes in TBI patients $(9,18)$. Conversely, concerns have been raised regarding no improved clinical outcomes with ICP monitoring, and possibly increased mortality rates from its use, at least in TBI patients $(7,21)$. A recent Cochrane review corroborated this, finding insufficient evidence for routine ICP monitoring in TBI patients (22). The major study considered in this review was the BEST-TRIP trial (23), which demonstrated that treatment guided by ICP-monitoring was not superior to treatment guided by the NWT and serial CT scans. This underscores the importance of the neurologic examination for clinical monitoring and guiding treatment decisions. Neurocritical care experts during the International Multidisciplinary Consensus Conference on multimodality monitoring in neurocritical care strongly recommend the use of ICP monitoring along with clinical examinations and other monitoring modalities to accurately prognosticate and guide treatment (10). In patients with hemispheric ischemic stroke and associated cerebral edema, ICP monitoring is not recommended (24). 
The Neurologic Wake-Up Test

126

127

128

129

130

131

132

133

134

135

136

137

138

139

140

141

142

143

144

145

146

147

148

149

150

151

152

153

154

155

156

157

158

159

160

161

162

163

164

165

166

167

CPP can be calculated with ICP monitoring, as CPP = MAP - ICP. A healthy brain has robust autoregulatory mechanisms to maintain CBF even in the face of volatile fluctuations in CPP and MAP. However, during brain injury, autoregulation is impaired, making perfusion of the brain passively dependent on blood pressure. Normally, CPP can be used as an estimate of cerebral perfusion. Nevertheless, as with ICP monitoring, the use of CPP monitoring is fraught with concerns over both clinical utility and the fact that there is no recognized appropriate value to aim for (25).

Highlighting this, the Brain Trauma Foundation recommends a CPP value between 50-70 mmHg (18). This is important, as CPP elevation past $70 \mathrm{mmHg}$ has been linked to poor outcomes in TBI patients, along with lung damage. CPP levels below $70 \mathrm{mmHg}$ have been associated with worsening brain hypoxia in patients (7). Andrews and colleagues found that low CPP along with hypotension was the best predictor of death in TBI patients (26). Additionally, there is great variability in outcomes. In one study half of the patients benefited from higher CPP, and the other half benefited from lower CPP (27). In an attempt to attenuate this variability, some authors recommend individualizing the CPP target $(12,25)$ through the use of cerebral autoregulation monitoring, which can be either a continuous or intermittent bedside measurement (28). Therefore, the role of CPP monitoring remains tenuous. CPP values need to be individually tailored to each patient, with more research required to establish if aggressive CPP management can improve patient outcomes.

$\underline{\mathrm{SjvO}}_{2}$

The purpose of $\mathrm{SjvO}_{2}$ monitoring is to acquire information pertaining to cerebral oxygen supply, perfusion, and consumption. It can be monitored either via fiberoptic catheters placed into the internal jugular bulb immediately distal to the jugular foramen, or intermittently checking jugular venous blood samples $(7,9)$. A noteworthy technical hurdle also exists, as falsely elevated $\mathrm{SjvO}_{2}$ can be measured due to the presence of only extracerebral blood in the jugular bulb (29). This depends on contamination from extracerebral sources via aspirating too quickly, or misplacing the catheter by only a couple of centimeters (30), which may lead to erroneous results and mismanagement (9). Moreover, this modality is of limited utility in severe global ischemia or very large infarcts, as $\mathrm{SjvO}_{2}$ can rebound upward due incomplete oxygen extraction by the ischemic tissue $(29,31)$.

Normal values range from 55-75\% oxygen saturation $\left(\mathrm{O}_{2}\right.$ sat). At baseline, shifts in $\mathrm{SjvO}_{2}$ reflect changes in CBF (32). Lower values are indicative of ischemia, either due to reduced blood flow, or greater oxygen extraction relative to cerebral perfusion, both of which are correlated with poor outcomes $(7,9)$. Additionally, both $\mathrm{SjvO}_{2}$ values of $<50 \%$ and $>75 \%$ are associated with poor patient outcomes (31). However, there are concerns about the clinical utility of this measurement, as one positron emission tomography (PET) study demonstrated that the $\mathrm{SjvO}_{2}$ value didn't drop to $<50 \%$ until $\sim 13 \%$ of the brain became ischemic (33). Therefore, the information garnered from this measurement is useful only as a global brain oxygenation monitoring tool, with poor correlation with regional brain oxygenation (34). In fact, normal range $\mathrm{SjvO}_{2}$ values are often obtained in the presence of ongoing focal ischemia, hyperemia, and/or shunting (9). Another consideration is that a high level of false positive desaturations are 
The Neurologic Wake-Up Test detected $(9,35)$, prompting unnecessary workup. Its role in monitoring patients in the NCCU has not yet been determined (7). Vidgeon et al. state that there is no solid evidence to support its use for ongoing clinical monitoring (9).

\section{$\underline{\mathrm{PbtiO}_{2}}$}

Direct monitoring of brain tissue oxygenation provides a continuous stream of information pertaining to focal oxygenation, with typical values ranging from $15-30 \mathrm{mmHg}$ (2-4 $\mathrm{kPa}$ ), and a critical ischemic threshold commonly established at $10 \mathrm{mmHg}(<1.33 \mathrm{kPa})$, which is indicative of brain hypoxia $(7,9)$. This measurement is carried out through a thin electrode placed into white matter, either in peri-ischemic at-risk tissue (the penumbra) for focal measurements, or in frontal white matter to estimate global cerebral oxygenation in diffuse brain injury $(7,9)$. Using this measure, ischemic changes with regional differences have been detected following TBI (36), and these transient periods of ischemia are correlated with worsened patient outcomes (37). In general, brain injured patients with brain hypoxia ( $\mathrm{PbtiO}_{2}<10 \mathrm{mmHg}$ ) have significantly poorer outcomes and increased mortality (38). A systematic review comparing $\mathrm{PbtiO}_{2}$-based therapy alongside ICP/CPP monitoring to ICP/CPP-based therapy alone reported a favorable outcome for the $\mathrm{PbtiO}_{2}$-based group (25, 39). However, Adamides et al. compared two groups of patients that both underwent $\mathrm{PbtiO}_{2}$ monitoring. One group received treatment based upon this measurement, and the other was simply monitored. Although the measurement-guided treatment group had decreased duration of hypoxia, patient outcomes were not improved (40).

$\mathrm{PbtiO}_{2}$ can also aid in identifying an individual's optimal CPP for mitigating hypoxia, and monitoring effects of hemodynamic treatment (12). One clinical trial demonstrated that decreased levels of $\mathrm{PbtiO}_{2}$ can occur even in the face of adequate CPP (41). This suggests combinations of multimodality monitoring are more effective and provide additional insight not garnered by either individually (7). Despite strong correlations between brain hypoxia and poor outcomes, and retrospective reviews suggesting some benefit to treatments guided by $\mathrm{PbtiO}_{2}$ measurements, high quality randomized trials are required to determine if guiding therapeutic interventions based upon this metric is beneficial (12, 25, 42). Consistently, $\mathrm{PbtiO}_{2}$-guided therapy and clinical outcomes remain subject to debate (42).

$\underline{\mathrm{MD}}$

Intracerebral MD can be utilized to measure brain neurochemistry through the insertion of a microdialysis catheter that contains a semipermeable hollow fiber membrane at its tip. This is attached to a perfusion pump that is subsequently perfused with a fluid that resembles the interstitial fluid in question (artificial CSF). This allows transport of molecules across a concentration gradient through the membrane via passive diffusion, allowing measurement of various chemicals, such as neurotransmitters, and metabolic substrates and products, like glucose, lactate, pyruvate, glycerol, glutamate, et cetera (7). The MD catheter is typically placed adjacent to a focal lesion to detect early metabolic alterations, such as near a vascular territory susceptible to vasospasm following subarachnoid hemorrhage (SAH), or the penumbra region of an infarct or mass lesion. It may also be placed in the non-dominant frontal region in the case of diffuse injury $(9,43)$.

MD measures the cellular bioenergetic and redox state of the monitored brain region, which is typically perturbed in brain injury. Ischemia and resultant lack of blood flow and 
The Neurologic Wake-Up Test

oxygenation shifts metabolism from the brain's obligatory aerobic condition to an anaerobic one, resulting in a lack of ATP production. (44). This is compounded by severe mitochondrial dysfunction and inhibition of pyruvate dehydrogenase (PDH) in TBI patients $(45,46)$, causing inhibition of oxidative phosphorylation. This results in a surge in lactate levels as a means to restore NAD+ levels, reflected by a high lactate to pyruvate ratio (LPR) $(44,46)$. Glutamate is elevated post-brain injury for two reasons: ATP is necessary to maintain baseline ionic equilibrium across various channels; thus, its absence causes massive glutamate release due to postsynaptic calcium entry, and glutamate reuptake and metabolism are ATP-dependent processes $(44,46)$. Glucose levels plummet due to either lack of blood flow, or glucose hyperutilization following TBI, both of which can reduce glucose concentration below critical thresholds (25). Glycerol elevation indicates decomposition of cell membranes associated with severe cellular damage (43). Correlating the microscopic anomalies with the macroscopic picture, these processes cause neuronal death, cellular edema, and elevated ICP (47).

As MD detects metabolic alterations, it can provide valuable clinical information about brain function following injury and impending metabolic crises. Its most promising application is detecting ischemia and neuronal damage at pre-clinical stages, allowing for early intervention to salvage brain tissue $(25,47)$. LPR is a sensitive marker of brain ischemia and redox state $(9,43)$. Elevated LPR measurements correlate with symptom severity and fatal outcomes after brain injury $(43,47)$. Elevated LPR $>25$ is associated with poor outcomes in TBI (9), and elevated LRP coupled with low glucose correlates with worsened outcomes in TBI and SAH patients (25, 48). Furthermore, one study showed that length of time spent with elevated LPR $>40$ correlated with frontal lobe atrophy at 6 months (49).

Additionally, MD is purported to aid in guiding optimal CPP targets (25, 47), although this has been inconsistent (50). Elevated levels of glutamate show similar predictive power as a proxy for ischemia $(9,43)$, and the degree of elevated glutamate correlates with poor patient outcomes $(47,51)$. However, this has been challenged by some $(47,52)$. Elevating glycerol levels $\geq 3$ days post TBI can be associated with ongoing neurologic deterioration or seizure activity $(9,47)$. Thus, MD offers unique insight into cellular bioenergetics and their perturbations following brain injury, possibly before clinical signs could be elicited on examination. There is increasing use of MD, and certain protocols have been established, with alarm levels of LPR set at $>30$, and/or glucose levels $<0.8 \mathrm{mmol} / \mathrm{l}$ (53). Despite the promising utility, its overall value as a tool for guiding clinical decision making has yet to be fully elucidated $(7,25,53)$.

Multimodality Neuromonitoring Conclusion

Each of these multimodal monitoring components provide unique and clinically relevant information pertaining to neurologic functioning. Multiple modalities can complement the information from one another synergistically, hence the rationale for using multiple monitoring modalities concurrently (9). For instance, Muizelaar, while evaluating the utility of multimodality monitoring to predict hypoperfusion, recommends utilizing a combination of ICP, $\mathrm{CPP}$, and $\mathrm{PbtiO}_{2}$ monitoring (54). Aligning with this, Smith et al. state that the simultaneous measurement of ICP and brain tissue oxygenation is a simple, logical approach, as a single probe can monitor both measurements (55). Accordingly, the Seattle International Brain Injury Consensus Conference (SIBICC) recently stated that $\mathrm{PbtiO}_{2}$ should be the second monitored variable after ICP (56). In another report, by utilizing machine learning, Raj and colleagues were 
The Neurologic Wake-Up Test

253

254

255

256

257

258

259

260

261

262

263

264

265

266

267

268

269

270

271

272

273

274

275

276

277

278

279

280

281

282

283

284

285

286

287

288

289

290

291

292

293

294

295

able to accurately predict mortality in TBI patients using only ICP, CPP, and MAP measurements (57). The accuracy was improved with the addition of a GCS score into the algorithm, demonstrating the key role of the neurologic examination.

Recently, the Neurocritical Care Society and the European Society of Intensive Care Medicine held a panel to evaluate and discuss the evidence of multimodality monitoring (12). They conclude that a single monitoring modality is demonstrably insufficient. Despite this, they state that there is no consensus on their use, and more studies are required to ascertain if it translates to improved patient outcomes. However, they underscore the importance of the neurologic exam and the NWT, stating that it remains a cornerstone in the accurate assessment of patients. The vast amounts of information gathered via these monitoring modalities, how to evaluate and integrate them, and their ability to guide optimal therapeutic plans is still being elucidated (10).

\section{The NWT}

Temporarily and intermittently stopping sedation of ventilated patients to mitigate the harmful effects of over sedation is termed a daily interruption of continuous sedation (DIS) trial. Though widely utilized and studied, firm recommendations are tenuous because of large scale reviews with conflicting conclusions about their utility $(3,58)$. Despite lacking firm recommendations for DIS protocols, the NWT, which involves a daily cessation of sedation for neurological examination purposes, is regarded as the gold-standard for evaluating patients with brain injury in the ICU and NCCU $(1,3,7,12,13,59-61)$. Neither neuroimaging, nor multimodality monitoring can replace the neurologic examination (62), and it remains the most valuable tool for the assessment of brain injured patients, from stroke (61), to SAH (63, 64), and TBI $(12,13,59)$. A recent intensive care symposium in Paris aiming to update neurocritical care recommendations states that the neurologic examination is indispensable for the accurate assessment of comatose patients, along with the simultaneous use of neuroimaging and multimodality monitoring (65). The SIBICC panel recommend a sedation holiday (an NWT) in TBI patients with ongoing ICP monitoring to facilitate an accurate neurologic exam (66). They could not reach consensus on absolute nor relative contraindications, but they do not endorse the NWT until ICP is within acceptable limits $(<22 \mathrm{mmHg})$ for at least 24 hours. This is in line with preexisting intracranial hypertension being regarded as an absolute contraindication to the NWT (13).

Importantly, the NWT is not akin to a true awakening response, but rather an arousal reaction (60). Essential components of the NWT include GCS rating of the motor component (GCS-M), by asking the patient to obey simple commands, such as moving an extremity, squeezing the practitioner's fingers, etc. If no responses are elicited, a painful stimulus is provided, such as a sternal rub, supraorbital pressure, mandibular pressure, or a trapezius squeeze, and the provoked motor response is recorded. The other essential components of the NWT include evaluation of pupil diameter with attention paid to anisocoria, both direct and indirect pupillary light reflexes, and any focal neurologic deficits along each extremity (3). The automated infrared pupillometer has emerged as a rapid, noninvasive neuromonitoring tool to provide an objective assessment of pupillary reactivity, and drastically increase reliability and sensitivity of the pupil examination (55, 67-69). Deterioration of the pupillary light reflex is a strong predictor of outcome after brain injury, and subtle pupillary changes are often a harbinger 
The Neurologic Wake-Up Test

of elevated ICP, secondary brain injury, cerebral edema, hydrocephalus, and intracranial shift (67).

Neuroworsening, defined as a reduction in GCS-M $\geq 2$ points, or development of pupillary anomalies, mandates further investigation (70). Irrespective of the utility of multimodality monitoring, the NWT remains integral in the overall evaluation of patients. Evolving pathology can be picked up earlier, and some deterioration may only be detected by physical examination (7). This helps in patient assessment, and in monitoring treatment effectiveness (12). Many patients may have ongoing damage without clear abnormalities picked up through other monitoring modalities (70). The NWT is especially useful following decompressive craniectomy, or cases of SAH-related vasospasm, as deterioration may occur before ICP elevations and neuroimaging changes are detected (63). In cases of temporal hematomas, brain herniation can occur without concomitant elevations in ICP $(15,71)$. In patients with cerebral edema secondary to hemispheric ischemic stroke, such as malignant middle cerebral artery (MCA) infarction, ICP monitoring is not recommended because ICP elevations do not occur for days, and midline shift and pupillary abnormalities often occur even with ICP values $<20 \mathrm{mmHg}(24,61,72)$ These cases necessitate NWTs for early detection. This may become more pertinent with the 2020 Brain Trauma Foundation update recommending decompressive craniectomy for control of late, medically refractory ICP elevation (73).

Despite presumed benefit provided by NWTs, some concerns have been raised pertaining to the acute stress response elicited with discontinuation of sedation. During each arousal, there is a significant acute stress response with SNS discharge that induces hypertension and tachycardia (60). This is reflected by significantly increased levels of stress hormones. Adrenocorticotrophic hormone (ACTH) can be increased by $72.5 \%$, cortisol by $30.7 \%$, epinephrine (E) by $87.5 \%$, and norepinephrine (NE) by $40.4 \%$ (74). However, the increased levels of NE do not reach levels required for augmenting the risk of microthrombi formation (75). These changes are mirrored by significantly increased ICP and CPP values, with a mean increase of $3 \mathrm{mmHg}$ and $8 \mathrm{mmHg}$, respectively. During the NWT, ICP reached an average value of $15.3 \mathrm{mmHg}$, and CPP reached an average value of $84.4 \mathrm{mmHg}$ (74).

Skoglund et al. explored ICP and CPP changes in TBI and SAH patients (21 patients) undergoing NWTs (127 total NWTs). In pooling all patients, they demonstrated a mean increase in ICP of $8 \mathrm{mmHg}$, reaching an average value of $>20 \mathrm{mmHg}$. The mean CPP increase was 5.2 $\mathrm{mmHg}$, reaching average values of $>81 \mathrm{mmHg}(63)$. There were important subgroup differences, with TBI patients showing higher ICP values at baseline and during the NWT, and SAH patients presenting with higher CPP values at baseline and greater changes during the NWT, indicating the need for patient stratification based upon injury type and baseline characteristics. Furthermore, highlighting the heterogeneity of brain injuries, there was great variability in these metrics. Several patients developed a sustained increase in ICP levels to > 30 mmHg for an average of 3.6 minutes. Similarly, some patients had a sustained decrease in CPP values to $\leq 50 \mathrm{mmHg}$ for an average of 10 minutes, and these reductions were far more common in TBI patients. Overall, in 23/127 trials, CPP decreased to $<50 \mathrm{mmHg}$ due to ICP $\geq 25 \mathrm{mmHg}$, although these were generally short-lived deviations. The average ICP values peaking at $>20$ mmHg were interpreted to be safe and well tolerated by the authors due to their mild and transient nature. However, those values could be consequential to some as preexisting 
The Neurologic Wake-Up Test

intracranial hypertension is an absolute contraindication to the NWT $(3,13)$. Consistently, they refrained from performing NWTs in clearly unstable patients and those with plateau waves, which are sudden rapid elevations of ICP to 50-100 mmHg due to cerebral vasodilation (76). In contrast to the current study (63), the previously discussed research by Skoglund and colleagues showed less dramatic ICP and CPP elevations in response to the NWT (74). Stover hypothesizes that these discrepancies may reflect a learning curve to the NWT, or involve examinations undertaken on less severely injured patients with preserved autoregulation (60). In either case, it certainly indicates the heterogeneity of brain injury and the unpredictable clinical course that may ensue (9).

Excluding those with preexisting intracranial hypertension, the increases in ICP and CCP were transient and interpreted to be well-tolerated without advancing neurologic deterioration (3). Additionally, though these increases occur, they are not met with alterations in overall cerebral metabolism or oxygenation, suggesting its safety in most patients $(1,12)$. Components of multimodality monitoring were evaluated for changes occurring due to the NWT (77). It was demonstrated that there were no significant changes in measures of glucose, lactate, pyruvate, glutamate, glycerol, or LPR as measured by MD. Similarly, changes in oxygenation as measured by both $\mathrm{PbtiO}_{2}$ and $\mathrm{SjvO}_{2}$ showed no significant alterations. Consistent with previous reports, ICP and CPP values significantly increased during the NWT, by $7.6 \mathrm{mmHg}$ and $6 \mathrm{mmHg}$, respectively, reaching values of $16.7 \mathrm{mmHg}$ and $94.4 \mathrm{mmHg}$. These reports demonstrate that although there is a stress response elicited by the NWT, and ICP and CPP elevations occur in parallel, neurochemical and cerebral perfusion alterations are minimal. This indicates that these perturbations are well tolerated, and are unlikely to cause secondary injury to the brain $(7,59)$.

In one prospective study of 20 patients (54 total NWTs), (78), upwards of 34\% of NWTs were not performed, as the patients were not seen as stable enough due to elevated ICP and need for continuous sedation. In those that received NWTs, upwards of 33\% were stopped due primarily to ICP-crisis (>20 mmHg), or systemic desaturation. Moreover, in those patients with NWT cessation, they noted a statistically significant reduction in $\mathrm{PbtiO}_{2}$ measures, decreasing from an average of $28 \mathrm{mmHg}$ to $19 \mathrm{mmHg}$, which is still well above hypoxic thresholds $(9,79)$. While not rising to the level of statistical significance, a trend was noted between lower brain glucose, higher total LPR, and neurologic deterioration from the NWT, which seems to corroborate the benefit of multiple simultaneous modalities of monitoring. Overall, however, there were no significant alterations in lactate, pyruvate, LPR, or glucose in patients undergoing NWTs. Moreover, as shown by Skoglund et al $(63,77)$, transiently increased ICP to $>20 \mathrm{mmHg}$ may not be as deleterious as presumed. If they are not coupled with concomitant metabolic indicators of ischemia or inadequate perfusion, it is unlikely that neurologic deterioration is occurring; in no studies heretofore has the NWT been shown to cause neurologic injury. Therefore, though patients that developed intracranial hypertension in response to the NWT had stoppage of the examination, the preponderance of data indicate most of these patients were likely to tolerate the exam without promoting neurologic injury. Nevertheless, differential findings in $\mathrm{PbtiO}_{2}$ measures between this report by Helbok et al. (78) and the aforementioned one by Skoglund et al. (77), further demonstrate the marked heterogeneity of brain injured patients and need for scrupulous patient stratification (60). An additional confounder between the two reports is that of considerably different sedative use. Helbok et al. (78) utilized a combination of propofol, midazolam, dexmedetomidine, and fentanyl, whereas Skoglund et al. 
The Neurologic Wake-Up Test

(77) used continuous propofol infusion with intermittent morphine administration. These significant differences make conclusions questionable, however, it may give insight into optimal sedative practices to facilitate successful NWTs.

Additional predictors of NWT failure were shown in a large 7-year study with 96 patients at one center (80). It demonstrated that $39.5 \%$ of their patients had discontinuation of NWTs. Of those patients with discontinued NWTs, it was due to neurologic deterioration in $71 \%$ of cases, with the remaining 26\% due to respiratory distress. Most neurologic deteriorations were due to no improvement in the neurologic exam, or intracranial hypertension (ICP $>20 \mathrm{mmHg}$ for $>5$ minutes). As previously discussed, these short-lived increases in ICP are not met with alterations in cerebral metabolism or subsequent neurologic deterioration, making it likely that these elevations were not clinically relevant. The significant number of patients displaying no improvement in their clinical exam is important, as the point of the NWT is to accurately assess neurologic functioning. However, although the examination did not change in those patients from before to after sedation cessation, it may have still played a role in long-term assessment if subtle changes were later recognized. They also identified two patient cohorts with a significantly increased probability of NWT failure: those with a subdural hematoma $>5 \mathrm{~mm}$ thick on first imaging, or initial GCS $<5$. Finally, they note that the patients that were unable to tolerate an NWT had significantly worse outcomes at 1 year, implicating the NWT as a longterm prognostic tool.

The transient elevations in ICP in response to the NWT is a point of clinical uncertainty. In some reports ICP elevations to $>20 \mathrm{mmHg}$ prompted immediate cessation of the NWT (78, $80)$, whereas in others, it was interpreted as safe and well-tolerated $(63,74,77)$. This discrepancy implicates the dose-time concept, the relevance of thresholds, and variational idiosyncrasies. Preexisting intracranial hypertension is a hard contraindication to the NWT (13). As measured by microdialysis and brain-oxygenation, the NWT generally shows no significant alterations even in the face of elevated ICP and CPP $(77,78)$. However, a minority of specific patients display extreme and unpredictable changes to ICP and CPP in response to the NWT (63), but concurrent microdialysis and $\mathrm{PbtiO}_{2}$ has not been undertaken to explore if those changes are mirrored by altered cerebral metabolism, oxygenation, and secondary deterioration. Importantly, even those volatile changes are transient. Most data indicate that sustained elevations in ICP, and ICP elevation refractory to medical management are deleterious and associated with worse outcomes (63, 70, 81). Consistently, the 2020 Brain Trauma Foundation update recommends decompressive craniectomy for ICP control only when prolonged and medically recalcitrant, noting late intervention improves mortality whereas early intervention does not $(73,82)$.

The concept of "ICP dose" is becoming increasingly investigated. It recognizes that ICP thresholds are arbitrary and meaningless without accounting for the time spent at "deleterious" levels, and without consideration for the complex interactions of ICP, cerebral blood flow, cerebral metabolism, and the feedback mechanisms involved in cerebral autoregulation, neurovascular coupling, and $\mathrm{CO}_{2}$ reactivity (83). Multiple studies have begun to investigate this, demonstrating an association between poorer clinical outcomes with greater time spent above certain ICP thresholds (84-86). In one of these reports, it was shown that increased ICP timedose was associated with higher mortality and poor outcomes, but no association was found between episodic ICP levels and outcomes (85). Helbok et al. point out that the injured brain is 
The Neurologic Wake-Up Test

not aware of thresholds, and that even a "normal ICP” does not guarantee adequate cerebral perfusion, as ICP-dependent changes in CPP are dynamic, and the threshold-based approach is an oversimplification of a complex pathophysiological process (83). In patients with borderline ICP values, they can be stratified and managed appropriately with the addition of clinical examinations and other neuromonitoring to determine the presence or absence of brain hypoxia, cerebral hypoperfusion, or metabolic distress, allowing an individualized approach (83). This concept lends more credence toward the NWT and its associated transient ICP excursions as safe and well-tolerated in a majority of patients.

While the NWT is widely used, there is little information about the clinical benefits procured by it in the literature. Theoretical rationale is a good starting point, but is incomplete on its own (59). Stocchetti et al. demonstrated that out of 449 TBI patients, $12.9 \%$ were misclassified as having a more severe brain injury due to sedation masking their neurologic functioning, precluding an accurate assessment (87). Only one randomized controlled trial on the NWT exists (88), which demonstrated a reduction in the duration of mechanical ventilation by an average of 3.9 days, and decreased ICU stay by 3 days, albeit neither of these measures were statistically significant. Importantly, the authors did not comment on any relevant neurologic information gathered via this intervention, only noting that it was safe and well-tolerated. There has been only one study directly investigating pertinent clinical information gained by performing NWTs (78), which showed that it rarely led to accrual of additional clinically relevant information $(3,89)$. In this study, when utilizing NWTs, they noted an increase in GCS and Full Outline of UnResponsiveness (FOUR) scores in half of their patients but did not comment on any change in treatment modality, nor associated prognosis, and in only 1 patient was a new focal neurologic deficit discovered. In that patient, increased brain lactate and decreased glucose was observed hours prior to the NWT, underscoring the utility of multimodality monitoring.

The NWT remains contemporaneously regarded as the sine qua non for optimal assessment of the brain-injured patient $(3,7,12,13,70,78)$. The limited amount of published literature suggests safety and tolerability in most patients, including those with ICP elevations during the NWT itself. At present, patients with pre-existing sustained intracranial hypertension, those with status epilepticus, marked hyperthermia, or undergoing barbiturate treatment have absolute contraindications to the NWT. Other indicators that a patient may be unable to tolerate an NWT include hemodynamic instability, ongoing sedation for the purposes of controlling agitation, respiratory distress, and seizure activity, recent myocardial ischemia, or as a primary treatment for ICP control. Individual patients with volatile ICP or CPP responses must be handled in a case-by-case basis with appropriate risk-benefit profiles appraised.

The reliability of the neurologic exam, its cost, and its ability to detect subtle deficits not picked up via multimodality monitoring make it indispensable. Multimodality monitoring can assist in ensuring cerebral metabolism and perfusion/oxygenation are adequate against the background of elevated ICP or a stable exam. This monitoring may be essential in those patients in whom NWTs are contraindicated. It may assist in individualizing treatment, and detecting metabolic distress before injury has completed. In one randomized controlled trial, ICP-guided treatment did not have better outcomes than clinical examination and neuroimaging alone (23). Overall, multimodality neuromonitoring should be seen as a compliment to the NWT, and vice 
The Neurologic Wake-Up Test

versa (55). More investigations are required to tease out the absolute clinical utility of the NWT, with specific regard to patient outcomes and management guidance (60).

\section{Is there an optimal frequency of performing NWTs?}

Another central question pertaining to NWTs is their optimal frequency of utilization. Unfortunately, there are a paucity of studies examining this issue, and no clear guidelines have been set. Furthermore, due to the NWT not being recommended in established TBI care guidelines (16), there is great variability in their utilization and frequency. However, these guidelines have recently come under scrutiny $(90,91)$. The recent SIBICC recommends a sedation holiday (NWT) to facilitate an accurate neurologic examination in severe TBI patients with ongoing ICP monitoring, but do not mention frequency (66). One report suggests that upwards of 50\% of NCCU centers in Scandinavian countries do not utilize NWTs (92), which may partly be explained by differences in sedative use. In those centers utilizing NWTs, the majority use daily, with sometimes twice daily checks $(7,59)$, and one center utilizes NWTs between 4-6 times per day (7).

This demonstrates the enormous variability in both use and frequency of NWTs, necessitating the need for more data and guidelines to be established to guide clinical practice. Indeed, only one official recommendation has been offered, from the European Society for Intensive Care Medicine (ESICM) NeuroIntensive Care Section (NIC) (13). They convened an expert panel and state that a daily, brief interruption of sedation is recommended to facilitate an accurate neurologic examination (an NWT) and improve outcomes, giving it moderate evidence and a strong recommendation. Additionally, they state that brain injured patients, ICU patients, and in general all critically ill patients, shoulder undergo a neurological examination on initial ICU admission, and at least once daily, giving it moderative evidence, and a best practice recommendation. They also note the clear contraindication, as previously stated, with DIS and NWTs not recommended in patients with preexisting intracranial hypertension, assigning it moderate evidence and a strong recommendation (13). Lastly, in their concluding remarks, they note that despite technological advances, the neurologic examination remains a foundation of accurate evaluation and prognostic assessment of neurologic function, pointing out the robust prognostic value of GCS scores and pupillary light responses. Therefore, the only concrete recommendation that has been put forth pertaining to the optimal frequency of NWTs is at minimum once daily. Randomized controlled trials will need to be undertaken utilizing differential NWT frequencies to gain insight into what the optimal frequency is, if different patient populations have an impact on this, and what influence injury type has. Thus, much more research will need to be carried out before concrete recommendations about NWT frequency can be given and guidelines administered.

\section{Choice of Sedative}

Another consideration is sedative selection. There are myriad sedating agents utilized in the ICU and NCCU, namely propofol, benzodiazepines, dexmedetomidine, opioids, and barbiturates. The most common agents utilized in ICUs and NCCUs are propofol and midazolam (7), and these may be used in conjunction with opioids for additional analgesia. Recently, dexmedetomidine has begun to see increasing use, and it represents another attractive option for sedation. They each possess their own risk vs benefit profiles. 
The Neurologic Wake-Up Test

Propofol enjoys ubiquitous ICU and NCCU use owing to several factors, including its neuroprotective effects. It is recommended to use for ICP control in current TBI-care guidelines (16), and it dampens cerebral metabolic oxygen demand (89). It possesses both rapid onset of action, and rapid plasma clearance, which facilitates reliable recovery of consciousness even after prolonged administration and thereby a consistent NWT. In higher doses it can induce burst suppression, which can effectively treat status epilepticus (89). It can abate oxidative stress, making it especially useful to combat the free radical generation in head injury (93). A microdialysis study in TBI patients comparing propofol to midazolam found no significant differences in measures of LPR, glutamate, glycerol, or glucose between the two agents over a 72-hour period (94). The doses utilized in that study may have been inadequate, and it was a short-term, small study, therefore more investigations are required to determine if propofol can improve outcomes via mitigating oxidative stress. Two retrospective studies have shown that sedation with propofol decreased mortality in TBI (95) and hemorrhagic stroke patients (96). It also has risks, including depressing effects on myocardial contractility, reductions in MAP, elevation in pancreatic enzymes and pancreatitis, and the development of propofol infusion syndrome (PRIS) (93). Though ICP reductions occur which mediate elevations in CPP, occasionally, MAP can fall to such an extent that CPP decreases, which requires judicious fluid resuscitation and vasopressor use. PRIS is a rare but extremely dangerous adverse effect of propofol infusion. It can lead to multi-organ failure and when suspected requires immediate cessation of propofol. Early warning signs include unexplained lactic acidosis, increasing need for inotropic agents, lipemia, and Brugada-like ECG changes (97). Risk factors for PRIS include large cumulative doses of propofol, young age, innate mitochondrial impairments, low carbohydrate intake, high fat intake (which propofol itself possesses, owing to the lipid formulation), critical illness, and catecholamine infusion (97). Importantly, PRIS is believed to be more common in TBI patients, largely owing to the larger doses often used for ICP control (93). For this reason, continuous propofol infusion should not be infused at a rate greater than 4 $\mathrm{mg} / \mathrm{kg} /$ hour for $>48$ hours (93). Propofol is an ideal agent for the NWT, and is widely recommended and utilized. Although rare, PRIS may limit its utility for long-term use in brain injured patients.

Midazolam has rapid onset with a rapid recovery. It decreases cerebral oxygen demand, although to a lesser extent than propofol, and has only slight influences on ICP levels (89). Despite possessing a short half-life, when infused continuously, its half-life increases due to both high lipid-solubility with associated tissue accumulation, and the presence of active metabolites that may be deleterious $(7,89)$. Consistently, midazolam use is associated with higher mortality rates in ICUs (98). Its persistent use leads to protracted sedation and prolonged time to awakening, which will confound a consistent NWT $(89,99)$. It also causes significant respiratory depression and inhibition of the cough reflex, along with issues of tolerance development and significant withdrawal symptoms upon cessation. Its use is also a risk factor for ICU delirium, which is itself associated with worse outcomes (93). Accordingly, its use increases ICU length of stay, and either propofol or dexmedetomidine sedation is preferred to improve clinical outcomes in intubated ICU patients (100). Midazolam is not recommended for use when serial NWTs are desired.

Dexmedetomidine is a sympatholytic agent that can achieve excellent sedation without respiratory depression, and possesses anxiolytic and analgesic properties. It has rapid onset of 
The Neurologic Wake-Up Test

action and elimination, does not accumulate in tissues, has a half-life of 6 minutes, and a terminal elimination half-life of 2-2.5 hours, making it ideal for a reliable NWT $(89,93,101)$. It also decreases ICP through reducing CBF, increases CPP, and reduces incidence of delirium (93). In one report, dexmedetomidine alone versus propofol alone showed no significant differences in measures of ICP, CPP, tachycardia, bradycardia, hypertension, or length of stay (102). Another report demonstrated that both midazolam and propofol increased the number of ventilator-associated events, whereas dexmedetomidine did not (103). Dexmedetomidine was associated with increased chance of extubation in that study. In a TBI murine model, dexmedetomidine showed significant neuroprotective effects (104), although human studies are required to corroborate these findings. Given its known role of impeding SNS discharge (105), it may decrease the injury-promoting catecholaminergic influence in TBI (106), and has been shown to decrease plasma cortisol after administration (107). This could make this choice of sedative especially useful in the NWT for lessening the NE and E excursions. Moreover, it has been shown that in comparison to propofol or midazolam, dexmedetomidine patients were better able to be aroused and cooperate, suggesting it may facilitate a more appropriate level of sedation, better enabling serial NWTs (108). Overall, this agent represents an extremely attractive option to utilize for long-term sedation and to facilitate an NWT. However, more studies are required, and given its limited clinical data, some authors do not currently recommend its use for sedation in brain-injured patients (89).

Most recommendations call for continuous propofol sedation, allowing for more frequent cessation of sedation for NWTs $(3,7,60,93)$. There has been some consideration of maintaining a low-dose of analgesics during NWTs (60). Thus, the few recommendations on the subject suggest using propofol to facilitate a smoother transition toward the NWT, with careful attention paid to the development of PRIS, and ensuring infusion rates remain less than $4 \mathrm{mg} / \mathrm{kg} / \mathrm{hour}$ unless for bolus ICP control. Dexmedetomidine has not yet received strong recommendations, especially in the NCCU, due to an absence of large-scale data. However, the existing literature indicates that dexmedetomidine can be safely and efficaciously used for brain-injured patients, and its rapid onset and short half-life devoid of residual tissue accumulation make it a very attractive choice to facilitate serial NWTs. It is already utilized in NCCUs that employ NWTs and has established feasibility and tolerability for the process (78). It is strongly recommended as the sedative agent of choice in the non-intubated patient (93).

Propofol is most strongly recommended due to widespread utilization, existing clinical research, and the preponderance of recommendations espousing its use. Despite this, dexmedetomidine can likely be used in its place. The primary choice of sedative should be individualized, and further based on comfort levels and experience. In non-intubated brain injured patients, or with the development of PRIS, dexmedetomidine should be the primary sedative. Midazolam use is not recommended for sedation because it precludes the ability to perform reliable, serial NWTs (93); it is associated with greater ICU length of stay, duration of mechanical ventilation, and delirium compared to propofol or dexmedetomidine (109); and is associated with dramatically prolonged time to awakening compared to propofol (110-113) and dexmedetomidine $(114,115)$. Despite the numerous pitfalls of midazolam use, it remains one of the most common sedatives utilized in ICUs (3). Therefore, in centers that primarily use midazolam, it must be recognized that NWTs may lack consistency due to bioaccumulation and residual sedation, with much greater time to awakening. Notwithstanding, when multimodality 
The Neurologic Wake-Up Test

599

600

601

602

603

\section{4}

605

606

607

608

monitoring is not utilized the NWT becomes the only source of information about neurologic function. This is already a reality in many lower-income countries and areas, with assessment coming from neurologic exams and serial CT imaging (116). In those cases, the NWT should still be done despite midazolam use, with acknowledgement that time to awakening is increased and day to day reliability of the exam diminished.

\section{Conclusion}

There are myriad benefits of sedation in the ICU and NCCU, but the most prominent in neuro-critical care is the reduction in cerebral metabolic demand. It is also widely recognized that the NWT is considered the gold-standard for evaluation of patients. Even with ubiquitous endorsement, its use cannot be justified if it does not provide additional clinically relevant information and guide decision making. Therefore, more studies are necessary to totally clarify its utility in clinical decision making.

Hard contraindications exist for patients with preexisting intracranial hypertension, hyperthermia, in status-epilepticus, or on barbiturate therapy. The NWT also induces a significant acute stress response, reflected by tachycardia, hypertension, and elevated ICP, and some individual patients show volatile reactions in these metrics. However, studies utilizing microdialysis and $\mathrm{PbtiO}_{2}$ have generally shown no significant alterations during the NWT even in the face of elevated ICP. Furthermore, the preponderance of data suggests CPP rises alongside ICP, indicating adequate perfusion. The ICP dose-time concept and the transient nature of ICP elevations with the NWT provide another layer of apparent safety. Importantly, there has yet to be evidence of secondary brain injury in response to the NWT.

The advent of multimodality neuromonitoring has added a tremendous amount of data pertaining to neurologic function into the physician's armamentarium. Despite this, those modalities have yet to demonstrate clearly improved patient outcomes, and uncertainties exist about their ability to change and guide clinical decisions. The information garnered from the NWT and multimodality monitoring are distinct and should be considered complementary.

There are few recommendations pertaining to an ideal frequency of NWTs, and under what circumstances, with the only available expert recommendation endorsing a frequency of once per day. The choice of sedative is the final consideration, with either propofol or dexmedetomidine as viable choices to facilitate consistent, serial NWTs. Most recommendations call for utilization of propofol. Dexmedetomidine is emerging as a feasible choice, with the existing literature showing benefits with its use. In non-intubated patients or patients with PRIS development, dexmedetomidine should be used. Midazolam use is not recommended for longterm sedation in general, nor as a good agent to facilitate consistent NWTs. In centers that primarily employ midazolam, there must be an appreciation for an inability to perform consistent, serial NWTs in a timely manner.

In patients without multimodal monitoring, the NWT should be utilized provided no hard contraindications exist. Additionally, vital signs must be stable before and throughout the examination (especially $\mathrm{O}_{2}$ saturation). The NWT should not be used if sedation is being used as a primary treatment for elevated ICP, severe agitation, or respiratory distress. Clinical suspicion should be used to identify those at the greatest risk of developing intracranial hypertension, and risk factors include an abnormal CT scan on admission, hypotension on admission, GCS-M < 3, 
641 pupillary anomalies, or a lengthy inability to follow the exam (10). Multimodal monitoring can 642 compensate for the inability to perform an NWT when contraindicated. Currently, based upon 643 one expert panel, NWTs can be recommended at a minimum of once per day. Either propofol or 644 dexmedetomidine represent good options for sedation. More research is required to elucidate the 645 clinical utility of the NWT, and establish guidelines about the optimal frequency of its utilization 646 with stratification based on injury type and patient population.

647

648

649

650

651

652

653

654

655

656

657

658

659

660

661

662

663

664

665

666

667

668

669

670

671 
The Neurologic Wake-Up Test

672

673

674

675

676

677

678

679

680

681

682

683

684

685

686

687

688

689

690

691

692

693

694

695

696

697

698

699

700

701

702

703

704

705

706

707

708

709

710

711

712

713

714

715

716

\section{Literature Cited:}

1. Lele A, Souter M. Sedation practices in the Neurocritical Care Unit. Journal of Neuroanaesthesiology and Critical Care (2016) 3(4):81-7. doi: 10.4103/2348-0548.174743.

2. Bruder N, Lassegue D, Pelissier D, Graziani N, Francois G. Energy expenditure and withdrawal of sedation in severe head-injured patients. Crit Care Med (1994) 22(7):1114-9. Epub 1994/07/01. doi: 10.1097/00003246-199407000-00011. PubMed PMID: 8026200.

3. Marklund N. The Neurological Wake-up Test-A Role in Neurocritical Care Monitoring of Traumatic Brain Injury Patients? Front Neurol (2017) 8:540. Epub 2017/11/02. doi: 10.3389/fneur.2017.00540. PubMed PMID: 29089921; PubMed Central PMCID: PMCPMC5650971. 4. Rhoney $\mathrm{DH}$, Parker D, Jr. Use of sedative and analgesic agents in neurotrauma patients: effects on cerebral physiology. Neurol Res (2001) 23(2-3):237-59. Epub 2001/04/26. doi: 10.1179/016164101101198398. PubMed PMID: 11320605.

5. Girard TD, Kress JP, Fuchs BD, Thomason JW, Schweickert WD, Pun BT, et al. Efficacy and safety of a paired sedation and ventilator weaning protocol for mechanically ventilated patients in intensive care (Awakening and Breathing Controlled trial): a randomised controlled trial. Lancet (2008) 371(9607):126-34. Epub 2008/01/15. doi: 10.1016/S0140-6736(08)60105-1. PubMed PMID: 18191684. 6. Kollef MH, Levy NT, Ahrens TS, Schaiff R, Prentice D, Sherman G. The use of continuous i.v. sedation is associated with prolongation of mechanical ventilation. Chest (1998) 114(2):541-8. Epub 1998/09/03. doi: 10.1378/chest.114.2.541. PubMed PMID: 9726743.

7. Skoglund K. The Neurological Wake-up Test in Neurocritical Care [Doctoral thesis, comprehensive summary]. Uppsala: Acta Universitatis Upsaliensis (2012).

8. Stocchetti N, Carbonara M, Citerio G, Ercole A, Skrifvars MB, Smielewski P, et al. Severe traumatic brain injury: targeted management in the intensive care unit. Lancet Neurol (2017) 16(6):45264. Epub 2017/05/16. doi: 10.1016/S1474-4422(17)30118-7. PubMed PMID: 28504109.

9. Vidgeon SD SA. Multimodal cerebral monitoring in traumatic brain injury. Sage Journals (2011). doi: $10.1177 / 175114371101200208$.

10. Le Roux P, Menon DK, Citerio G, Vespa P, Bader MK, Brophy GM, et al. Consensus summary statement of the International Multidisciplinary Consensus Conference on Multimodality Monitoring in Neurocritical Care : a statement for healthcare professionals from the Neurocritical Care Society and the European Society of Intensive Care Medicine. Intensive Care Med (2014) 40(9):1189-209. Epub 2014/08/21. doi: 10.1007/s00134-014-3369-6. PubMed PMID: 25138226.

11. Gill M, Windemuth R, Steele R, Green SM. A comparison of the Glasgow Coma Scale score to simplified alternative scores for the prediction of traumatic brain injury outcomes. Ann Emerg Med (2005) 45(1):37-42. Epub 2005/01/07. doi: 10.1016/j.annemergmed.2004.07.429. PubMed PMID: 15635308.

12. Citerio G, Oddo M, Taccone FS. Recommendations for the use of multimodal monitoring in the neurointensive care unit. Curr Opin Crit Care (2015) 21(2):113-9. Epub 2015/02/18. doi: 10.1097/MCC.0000000000000179. PubMed PMID: 25689123.

13. Sharshar T, Citerio G, Andrews PJ, Chieregato A, Latronico N, Menon DK, et al. Neurological examination of critically ill patients: a pragmatic approach. Report of an ESICM expert panel. Intensive Care Med (2014) 40(4):484-95. Epub 2014/02/14. doi: 10.1007/s00134-014-3214-y. PubMed PMID: 24522878.

14. Bouzat $\mathrm{P}$, Oddo $\mathrm{M}$, Payen JF. Transcranial Doppler after traumatic brain injury: is there a role? Curr Opin Crit Care (2014) 20(2):153-60. Epub 2014/02/18. doi: 10.1097/MCC.0000000000000071. PubMed PMID: 24531654. 
The Neurologic Wake-Up Test

717 15. Rangel-Castilla L, Gopinath S, Robertson CS. Management of intracranial hypertension. Neurol

718 Clin (2008) 26(2):521-41, x. Epub 2008/06/03. doi: 10.1016/j.ncl.2008.02.003. PubMed PMID: 18514825;

719 PubMed Central PMCID: PMCPMC2452989.

720 16. Carney N, Totten AM, O'Reilly C, Ullman JS, Hawryluk GW, Bell MJ, et al. Guidelines for the

721 Management of Severe Traumatic Brain Injury, Fourth Edition. Neurosurgery (2017) 80(1):6-15. Epub

722 2016/09/23. doi: 10.1227/NEU.0000000000001432. PubMed PMID: 27654000.

723 17. Stocchetti N, Penny KI, Dearden M, Braakman R, Cohadon F, lannotti F, et al. Intensive care management of head-injured patients in Europe: a survey from the European brain injury consortium. Intensive Care Med (2001) 27(2):400-6. Epub 2001/06/09. doi: 10.1007/s001340000825. PubMed PMID: 11396285.

18. The Brain Trauma Foundation. The American Association of Neurological Surgeons. The Joint Section on Neurotrauma and Critical Care. Indications for intracranial pressure monitoring. $J$ Neurotrauma (2000) 17(6-7):479-91. Epub 2000/08/11. doi: 10.1089/neu.2000.17.479. PubMed PMID: 10937890.

19. Shen L, Wang Z, Su Z, Qiu S, Xu J, Zhou Y, et al. Effects of Intracranial Pressure Monitoring on Mortality in Patients with Severe Traumatic Brain Injury: A Meta-Analysis. PLoS One (2016) 11(12):e0168901. Epub 2016/12/29. doi: 10.1371/journal.pone.0168901. PubMed PMID: 28030638; PubMed Central PMCID: PMCPMC5193438.

20. Alberico AM, Ward JD, Choi SC, Marmarou A, Young HF. Outcome after severe head injury. Relationship to mass lesions, diffuse injury, and ICP course in pediatric and adult patients. J Neurosurg (1987) 67(5):648-56. Epub 1987/11/01. doi: 10.3171/jns.1987.67.5.0648. PubMed PMID: 3668633.

21. Piccinini A, Lewis M, Benjamin E, Aiolfi A, Inaba K, Demetriades D. Intracranial pressure monitoring in severe traumatic brain injuries: a closer look at level 1 trauma centers in the United States. Injury (2017) 48(9):1944-50. Epub 2017/05/13. doi: 10.1016/j.injury.2017.04.033. PubMed PMID: 28495204.

22. Forsyth RJ, Raper J, Todhunter E. Routine intracranial pressure monitoring in acute coma. Cochrane Database Syst Rev (2015) (11):CD002043. Epub 2015/11/03. doi: 10.1002/14651858.CD002043.pub3. PubMed PMID: 26522651.

23. Chesnut RM, Temkin N, Carney N, Dikmen S, Rondina C, Videtta W, et al. A trial of intracranialpressure monitoring in traumatic brain injury. N Engl J Med (2012) 367(26):2471-81. Epub 2012/12/14. doi: 10.1056/NEJMoa1207363. PubMed PMID: 23234472; PubMed Central PMCID: PMCPMC3565432. 24. Wijdicks EF, Sheth KN, Carter BS, Greer DM, Kasner SE, Kimberly WT, et al. Recommendations for the management of cerebral and cerebellar infarction with swelling: a statement for healthcare professionals from the American Heart Association/American Stroke Association. Stroke (2014) 45(4):1222-38. Epub 2014/02/01. doi: 10.1161/01.str.0000441965.15164.d6. PubMed PMID: 24481970. 25. Kirkman MA, Smith M. Intracranial pressure monitoring, cerebral perfusion pressure estimation, and ICP/CPP-guided therapy: a standard of care or optional extra after brain injury? Br J Anaesth (2014) 112(1):35-46. Epub 2013/12/03. doi: 10.1093/bja/aet418. PubMed PMID: 24293327.

26. Andrews PJ, Sleeman DH, Statham PF, McQuatt A, Corruble V, Jones PA, et al. Predicting recovery in patients suffering from traumatic brain injury by using admission variables and physiological data: a comparison between decision tree analysis and logistic regression. J Neurosurg (2002) 97(2):32636. Epub 2002/08/21. doi: 10.3171/jns.2002.97.2.0326. PubMed PMID: 12186460.

759 27. Elf K, Nilsson P, Ronne-Engstrom E, Howells T, Enblad P. Cerebral perfusion pressure between 50 760 and $60 \mathrm{~mm} \mathrm{Hg}$ may be beneficial in head-injured patients: a computerized secondary insult monitoring 761 study. Neurosurgery (2005) 56(5):962-71; discussion -71. Epub 2005/04/28. PubMed PMID: 15854244. 
The Neurologic Wake-Up Test

762

763

764

765

766

767

768

769

770

771

772

773

774

775

776

777

778

779

780

781

782

783

784

785

786

787

788

789

790

791

792

793

794

795

796

797

798

799

800

801

802

803

804

805

806

807

28. Czosnyka M, Miller C, Participants in the International Multidisciplinary Consensus Conference on Multimodality M. Monitoring of cerebral autoregulation. Neurocrit Care (2014) 21 Suppl 2:S95-102. Epub 2014/09/12. doi: 10.1007/s12028-014-0046-0. PubMed PMID: 25208679.

29. Gopinath SP, Valadka AB, Uzura M, Robertson CS. Comparison of jugular venous oxygen saturation and brain tissue Po2 as monitors of cerebral ischemia after head injury. Crit Care Med (1999) 27(11):2337-45. Epub 1999/12/01. PubMed PMID: 10579245.

30. Shaaban Ali M, Harmer M, Latto I. Jugular bulb oximetry during cardiac surgery. Anaesthesia (2001) 56(1):24-37. Epub 2001/02/13. doi: 10.1046/j.1365-2044.2001.01707.x. PubMed PMID: 11167432.

31. Dash HH, Chavali S. Management of traumatic brain injury patients. Korean J Anesthesiol (2018) 71(1):12-21. Epub 2018/02/15. doi: 10.4097/kjae.2018.71.1.12. PubMed PMID: 29441170; PubMed Central PMCID: PMCPMC5809702.

32. Prabhakar H, Sandhu K, Bhagat H, Durga P, Chawla R. Current concepts of optimal cerebral perfusion pressure in traumatic brain injury. J Anaesthesiol Clin Pharmacol (2014) 30(3):318-27. Epub 2014/09/06. doi: 10.4103/0970-9185.137260. PubMed PMID: 25190937; PubMed Central PMCID: PMCPMC4152669.

33. Gupta AK, Hutchinson PJ, Al-Rawi P, Gupta S, Swart M, Kirkpatrick PJ, et al. Measuring brain tissue oxygenation compared with jugular venous oxygen saturation for monitoring cerebral oxygenation after traumatic brain injury. Anesth Analg (1999) 88(3):549-53. Epub 1999/03/11. PubMed PMID: 10072004.

34. Coles JP. Regional ischemia after head injury. Curr Opin Crit Care (2004) 10(2):120-5. Epub 2004/04/13. PubMed PMID: 15075722.

35. Artru F, Dailler F, Burel E, Bodonian C, Grousson S, Convert J, et al. Assessment of jugular blood oxygen and lactate indices for detection of cerebral ischemia and prognosis. J Neurosurg Anesthesiol (2004) 16(3):226-31. Epub 2004/06/24. doi: 10.1097/00008506-200407000-00007. PubMed PMID: 15211160 .

36. Rao GS, Durga P. Changing trends in monitoring brain ischemia: from intracranial pressure to cerebral oximetry. Curr Opin Anaesthesiol (2011) 24(5):487-94. Epub 2011/07/30. doi: 10.1097/ACO.0b013e32834a8965. PubMed PMID: 21799403.

37. van den Brink WA, van Santbrink H, Steyerberg EW, Avezaat CJ, Suazo JA, Hogesteeger C, et al. Brain oxygen tension in severe head injury. Neurosurgery (2000) 46(4):868-76; discussion 76-8. Epub 2000/04/14. doi: 10.1097/00006123-200004000-00018. PubMed PMID: 10764260.

38. Maloney-Wilensky E, Gracias V, Itkin A, Hoffman K, Bloom S, Yang W, et al. Brain tissue oxygen and outcome after severe traumatic brain injury: a systematic review. Crit Care Med (2009) 37(6):205763. Epub 2009/04/23. doi: 10.1097/CCM.0b013e3181a009f8. PubMed PMID: 19384213.

39. Nangunoori R, Maloney-Wilensky E, Stiefel M, Park S, Andrew Kofke W, Levine JM, et al. Brain tissue oxygen-based therapy and outcome after severe traumatic brain injury: a systematic literature review. Neurocrit Care (2012) 17(1):131-8. Epub 2011/08/17. doi: 10.1007/s12028-011-9621-9. PubMed PMID: 21845489.

40. Adamides AA, Cooper DJ, Rosenfeldt FL, Bailey MJ, Pratt N, Tippett N, et al. Focal cerebral oxygenation and neurological outcome with or without brain tissue oxygen-guided therapy in patients with traumatic brain injury. Acta Neurochir (Wien) (2009) 151(11):1399-409. Epub 2009/09/04. doi: 10.1007/s00701-009-0398-y. PubMed PMID: 19727549.

41. Bohman LE, Heuer GG, Macyszyn L, Maloney-Wilensky E, Frangos S, Le Roux PD, et al. Medical management of compromised brain oxygen in patients with severe traumatic brain injury. Neurocrit Care (2011) 14(3):361-9. Epub 2011/03/12. doi: 10.1007/s12028-011-9526-7. PubMed PMID: 21394543. 
The Neurologic Wake-Up Test

808 42. Martini RP, Deem S, Treggiari MM. Targeting brain tissue oxygenation in traumatic brain injury. 809 Respir Care (2013) 58(1):162-72. Epub 2012/12/29. doi: 10.4187/respcare.01942. PubMed PMID: 81023271826.

811 43. Bellander BM, Cantais E, Enblad P, Hutchinson P, Nordstrom CH, Robertson C, et al. Consensus meeting on microdialysis in neurointensive care. Intensive Care Med (2004) 30(12):2166-9. Epub 2004/11/19. doi: 10.1007/s00134-004-2461-8. PubMed PMID: 15549254.

814 44. Magistretti PJ, Allaman I. A cellular perspective on brain energy metabolism and functional imaging. Neuron (2015) 86(4):883-901. Epub 2015/05/23. doi: 10.1016/j.neuron.2015.03.035. PubMed PMID: 25996133. 45. Sharma P, Benford B, Li ZZ, Ling GS. Role of pyruvate dehydrogenase complex in traumatic brain injury and Measurement of pyruvate dehydrogenase enzyme by dipstick test. J Emerg Trauma Shock (2009) 2(2):67-72. Epub 2009/06/30. doi: 10.4103/0974-2700.50739. PubMed PMID: 19561963; PubMed Central PMCID: PMCPMC2700588.

821 46. Veech RL, Valeri CR, Vanltallie TB. The mitochondrial permeability transition pore provides a key to the diagnosis and treatment of traumatic brain injury. IUBMB Life (2012) 64(2):203-7. Epub 2012/01/14. doi: 10.1002/iub.590. PubMed PMID: 22241645; PubMed Central PMCID: PMCPMC3272646.

47. Tisdall MM, Smith M. Cerebral microdialysis: research technique or clinical tool. Br J Anaesth (2006) 97(1):18-25. Epub 2006/05/16. doi: 10.1093/bja/ael109. PubMed PMID: 16698861.

48. Kett-White R, Hutchinson PJ, Al-Rawi PG, Gupta AK, Pickard JD, Kirkpatrick PJ. Adverse cerebral events detected after subarachnoid hemorrhage using brain oxygen and microdialysis probes. Neurosurgery (2002) 50(6):1213-21; discussion 21-2. Epub 2002/05/23. doi: 10.1097/00006123200206000-00008. PubMed PMID: 12015838. 49. Marcoux J, McArthur DA, Miller C, Glenn TC, Villablanca P, Martin NA, et al. Persistent metabolic crisis as measured by elevated cerebral microdialysis lactate-pyruvate ratio predicts chronic frontal lobe brain atrophy after traumatic brain injury. Crit Care Med (2008) 36(10):2871-7. Epub 2008/09/04. doi: 10.1097/CCM.0b013e318186a4a0. PubMed PMID: 18766106. exhibits persistent elevation of lactate/pyruvate ratio independent of cerebral perfusion pressure. Crit Care Med (2007) 35(4):1153-60. Epub 2007/03/06. doi: 10.1097/01.CCM.0000259466.66310.4F. PubMed PMID: 17334254.

839 51. Zeiler FA, Thelin EP, Helmy A, Czosnyka M, Hutchinson PJA, Menon DK. A systematic review of cerebral microdialysis and outcomes in TBI: relationships to patient functional outcome, neurophysiologic measures, and tissue outcome. Acta Neurochir (Wien) (2017) 159(12):2245-73. Epub 2017/10/11. doi: 10.1007/s00701-017-3338-2. PubMed PMID: 28988334; PubMed Central PMCID: PMCPMC5686263.

52. Obrenovitch TP, Urenjak J. Is high extracellular glutamate the key to excitotoxicity in traumatic brain injury? J Neurotrauma (1997) 14(10):677-98. Epub 1997/12/31. doi: 10.1089/neu.1997.14.677. PubMed PMID: 9383088.

53. Hillered L, Persson L, Nilsson P, Ronne-Engstrom E, Enblad P. Continuous monitoring of cerebral metabolism in traumatic brain injury: a focus on cerebral microdialysis. Curr Opin Crit Care (2006)

850 54. Muizelaar JP. Multimodal monitoring after traumatic brain injury: useless or useful? Crit Care 851 Med (2015) 43(2):506-7. Epub 2015/01/20. doi: 10.1097/CCM.0000000000000792. PubMed PMID: 85225599489. 
The Neurologic Wake-Up Test

55. Smith M. Multimodality Neuromonitoring in Adult Traumatic Brain Injury: A Narrative Review. Anesthesiology (2018) 128(2):401-15. Epub 2017/09/25. doi: 10.1097/ALN.0000000000001885. PubMed PMID: 28938277.

56. Chesnut R, Aguilera S, Buki A, Bulger E, Citerio G, Cooper DJ, et al. A management algorithm for adult patients with both brain oxygen and intracranial pressure monitoring: the Seattle International Severe Traumatic Brain Injury Consensus Conference (SIBICC). Intensive Care Med (2020) 46(5):919-29. Epub 2020/01/23. doi: 10.1007/s00134-019-05900-x. PubMed PMID: 31965267; PubMed Central PMCID: PMCPMC7210240.

57. Raj R, Luostarinen T, Pursiainen E, Posti JP, Takala RSK, Bendel S, et al. Machine learning-based dynamic mortality prediction after traumatic brain injury. Sci Rep (2019) 9(1):17672. Epub 2019/11/30. doi: 10.1038/s41598-019-53889-6. PubMed PMID: 31776366; PubMed Central PMCID: PMCPMC6881446.

58. Burry L, Rose L, McCullagh IJ, Fergusson DA, Ferguson ND, Mehta S. Daily sedation interruption versus no daily sedation interruption for critically ill adult patients requiring invasive mechanical ventilation. Cochrane Database Syst Rev (2014) (7):CD009176. Epub 2014/07/10. doi: 10.1002/14651858.CD009176.pub2. PubMed PMID: 25005604; PubMed Central PMCID: PMCPMC6517142.

59. Helbok R, Badjatia N. Is daily awakening always safe in severely brain injured patients? Neurocrit Care (2009) 11(2):133-4. Epub 2009/08/12. doi: 10.1007/s12028-009-9262-4. PubMed PMID: 19669605. 60. Stover JF. Arousal from sedation in wake-up tests requires careful risk stratification. Crit Care Med (2012) 40(1):338-40. Epub 2011/12/20. doi: 10.1097/CCM.0b013e31823291bf. PubMed PMID: 22179372.

61. Jeon SB, Koh Y, Choi HA, Lee K. Critical care for patients with massive ischemic stroke. J Stroke (2014) 16(3):146-60. Epub 2014/10/21. doi: 10.5853/jos.2014.16.3.146. PubMed PMID: 25328873; PubMed Central PMCID: PMCPMC4200590.

62. Payen JF, Francony G, Canet C, Coppo F, Fauvage B. [Sedation in neurointensive care unit]. Ann Fr Anesth Reanim (2009) 28(12):1015-9. Epub 2009/12/01. doi: 10.1016/j.annfar.2009.10.003. PubMed PMID: 19945245.

63. Skoglund K, Enblad P, Marklund N. Effects of the neurological wake-up test on intracranial pressure and cerebral perfusion pressure in brain-injured patients. Neurocrit Care (2009) 11(2):135-42. Epub 2009/08/01. doi: 10.1007/s12028-009-9255-3. PubMed PMID: 19644774.

64. Petridis AK, Beseoglu K, Steiger HJ. The clinical examination in the patient with subarachnoid hemorrhage is still the most reliable parameter for predicting pathophysiological changes. Surg Neurol Int (2017) 8:294. Epub 2017/12/30. doi: 10.4103/sni.sni_332_17. PubMed PMID: 29285410; PubMed Central PMCID: PMCPMC5735437.

65. Oddo M, Bracard S, Cariou A, Chanques G, Citerio G, Clerckx B, et al. Update in Neurocritical Care: a summary of the 2018 Paris international conference of the French Society of Intensive Care. Ann Intensive Care (2019) 9(1):47. Epub 2019/04/18. doi: 10.1186/s13613-019-0523-x. PubMed PMID: 30993550; PubMed Central PMCID: PMCPMC6468018.

66. Hawryluk GWJ, Aguilera S, Buki A, Bulger E, Citerio G, Cooper DJ, et al. A management algorithm for patients with intracranial pressure monitoring: the Seattle International Severe Traumatic Brain Injury Consensus Conference (SIBICC). Intensive Care Med (2019) 45(12):1783-94. Epub 2019/10/30. doi: 10.1007/s00134-019-05805-9. PubMed PMID: 31659383; PubMed Central PMCID: PMCPMC6863785. 67. Lussier BL, Olson DM, Aiyagari V. Automated Pupillometry in Neurocritical Care: Research and Practice. Curr Neurol Neurosci Rep (2019) 19(10):71. Epub 2019/08/24. doi: 10.1007/s11910-019-0994-z. PubMed PMID: 31440851. 
The Neurologic Wake-Up Test

68. Couret D, Boumaza D, Grisotto C, Triglia T, Pellegrini L, Ocquidant P, et al. Reliability of standard pupillometry practice in neurocritical care: an observational, double-blinded study. Crit Care (2016) 20:99. Epub 2016/04/14. doi: 10.1186/s13054-016-1239-z. PubMed PMID: 27072310; PubMed Central PMCID: PMCPMC4828754.

69. Suys T, Bouzat P, Marques-Vidal P, Sala N, Payen JF, Rossetti AO, et al. Automated quantitative pupillometry for the prognostication of coma after cardiac arrest. Neurocrit Care (2014) 21(2):300-8. Epub 2014/04/25. doi: 10.1007/s12028-014-9981-z. PubMed PMID: 24760270.

70. Maas Al, Stocchetti N, Bullock R. Moderate and severe traumatic brain injury in adults. Lancet Neurol (2008) 7(8):728-41. Epub 2008/07/19. doi: 10.1016/S1474-4422(08)70164-9. PubMed PMID: 18635021.

71. Stevens RD, Shoykhet M, Cadena R. Emergency Neurological Life Support: Intracranial Hypertension and Herniation. Neurocrit Care (2015) 23 Suppl 2:S76-82. Epub 2015/10/07. doi: 10.1007/s12028-015-0168-z. PubMed PMID: 26438459; PubMed Central PMCID: PMCPMC4791176. 72. Poca MA, Benejam B, Sahuquillo J, Riveiro M, Frascheri L, Merino MA, et al. Monitoring intracranial pressure in patients with malignant middle cerebral artery infarction: is it useful? J Neurosurg (2010) 112(3):648-57. Epub 2009/08/12. doi: 10.3171/2009.7.JNS081677. PubMed PMID: 19663552.

73. Hawryluk GWJ, Rubiano AM, Totten AM, O'Reilly C, Ullman JS, Bratton SL, et al. Guidelines for the Management of Severe Traumatic Brain Injury: 2020 Update of the Decompressive Craniectomy Recommendations. Neurosurgery (2020) 87(3):427-34. Epub 2020/08/08. doi: 10.1093/neuros/nyaa278. PubMed PMID: 32761068; PubMed Central PMCID: PMCPMC7426189.

74. Skoglund K, Enblad P, Hillered L, Marklund N. The neurological wake-up test increases stress hormone levels in patients with severe traumatic brain injury. Crit Care Med (2012) 40(1):216-22. Epub 2011/12/20. doi: 10.1097/CCM.0b013e31822d7dbd. PubMed PMID: 22179339.

75. Tschuor C, Asmis LM, Lenzlinger PM, Tanner M, Harter L, Keel M, et al. In vitro norepinephrine significantly activates isolated platelets from healthy volunteers and critically ill patients following severe traumatic brain injury. Crit Care (2008) 12(3):R80. Epub 2008/06/20. doi: 10.1186/cc6931. PubMed PMID: 18564410; PubMed Central PMCID: PMCPMC2481479.

76. Daley ML, Leffler CW, Czosnyka M, Pickard JD. Plateau waves: changes of cerebrovascular pressure transmission. Acta Neurochir Suppl (2005) 95:327-32. Epub 2006/02/09. doi: 10.1007/3-21132318-x_67. PubMed PMID: 16463875; PubMed Central PMCID: PMCPMC1444891.

77. Skoglund K, Hillered L, Purins K, Tsitsopoulos PP, Flygt J, Engquist H, et al. The neurological wake-up test does not alter cerebral energy metabolism and oxygenation in patients with severe traumatic brain injury. Neurocrit Care (2014) 20(3):413-26. Epub 2013/08/13. doi: 10.1007/s12028-0139876-4. PubMed PMID: 23934408.

78. Helbok R, Kurtz P, Schmidt MJ, Stuart MR, Fernandez L, Connolly SE, et al. Effects of the neurological wake-up test on clinical examination, intracranial pressure, brain metabolism and brain tissue oxygenation in severely brain-injured patients. Crit Care (2012) 16(6):R226. Epub 2012/11/29. doi: 10.1186/cc11880. PubMed PMID: 23186037; PubMed Central PMCID: PMCPMC3672610.

79. Roh D, Park S. Brain Multimodality Monitoring: Updated Perspectives. Curr Neurol Neurosci Rep (2016) 16(6):56. Epub 2016/04/21. doi: 10.1007/s11910-016-0659-0. PubMed PMID: 27095434; PubMed Central PMCID: PMCPMC4863980.

80. Esnault P, Montcriol A, D'Aranda E, Bordes J, Goutorbe $P$, Boret $H$, et al. Early neurological wakeup test in intubated brain-injured patients: A long-term, single-centre experience. Aust Crit Care (2017) 30(5):273-8. Epub 2016/11/20. doi: 10.1016/j.aucc.2016.10.002. PubMed PMID: 27856146. 
The Neurologic Wake-Up Test

944 81. Ryttlefors M, Howells T, Nilsson P, Ronne-Engstrom E, Enblad P. Secondary insults in 945 subarachnoid hemorrhage: occurrence and impact on outcome and clinical deterioration. Neurosurgery 946 (2007) 61(4):704-14; discussion 14-5. Epub 2007/11/08. doi: 10.1227/01.NEU.0000298898.38979.E3. 947 PubMed PMID: 17986931.

948 82. Myburgh JA. Intracranial pressure thresholds in severe traumatic brain injury: Pro. Intensive Care 949 Med (2018) 44(8):1315-7. Epub 2018/07/07. doi: 10.1007/s00134-018-5264-z. PubMed PMID: 29978389.

83. Helbok R, Meyfroidt G, Beer R. Intracranial pressure thresholds in severe traumatic brain injury: Con : The injured brain is not aware of ICP thresholds! Intensive Care Med (2018) 44(8):1318-20. Epub 2018/07/07. doi: 10.1007/s00134-018-5249-y. PubMed PMID: 29978388.

84. Kahraman S, Dutton RP, Hu P, Xiao Y, Aarabi B, Stein DM, et al. Automated measurement of "pressure times time dose" of intracranial hypertension best predicts outcome after severe traumatic brain injury. J Trauma (2010) 69(1):110-8. Epub 2009/12/30. doi: 10.1097/TA.0b013e3181c99853. PubMed PMID: 20038855.

85. Sheth KN, Stein DM, Aarabi B, Hu P, Kufera JA, Scalea TM, et al. Intracranial pressure dose and outcome in traumatic brain injury. Neurocrit Care (2013) 18(1):26-32. Epub 2012/10/12. doi: 10.1007/s12028-012-9780-3. PubMed PMID: 23055087.

86. Vik A, Nag T, Fredriksli OA, Skandsen T, Moen KG, Schirmer-Mikalsen K, et al. Relationship of "dose" of intracranial hypertension to outcome in severe traumatic brain injury. J Neurosurg (2008) 109(4):678-84. Epub 2008/10/02. doi: 10.3171/JNS/2008/109/10/0678. PubMed PMID: 18826355. 87. Stocchetti N, Pagan F, Calappi E, Canavesi K, Beretta L, Citerio G, et al. Inaccurate early assessment of neurological severity in head injury. J Neurotrauma (2004) 21(9):1131-40. Epub 2004/09/30. doi: 10.1089/neu.2004.21.1131. PubMed PMID: 15453984.

88. Anifantaki S, Prinianakis G, Vitsaksaki E, Katsouli V, Mari S, Symianakis A, et al. Daily interruption of sedative infusions in an adult medical-surgical intensive care unit: randomized controlled trial. $J$ Adv Nurs (2009) 65(5):1054-60. Epub 2009/04/29. doi: 10.1111/j.1365-2648.2009.04967.x. PubMed PMID: 19399980.

89. Oddo M, Crippa IA, Mehta S, Menon D, Payen JF, Taccone FS, et al. Optimizing sedation in patients with acute brain injury. Crit Care (2016) 20(1):128. Epub 2016/05/06. doi: 10.1186/s13054-0161294-5. PubMed PMID: 27145814; PubMed Central PMCID: PMCPMC4857238.

90. Dickerman R, Reynolds A, Williamson J, Winters K. Letter: Guidelines for the Management of Severe Traumatic Brain Injury, Fourth Edition. Neurosurgery (2017) 81(4):E50. Epub 2017/09/22. doi: 10.1093/neuros/nyx308. PubMed PMID: 28934444.

91. Meyfroidt G, Citerio G. Letter: Guidelines for the Management of Severe Traumatic Brain Injury, Fourth Edition. Neurosurgery (2017) 81(1):E1. Epub 2017/04/06. doi: 10.1093/neuros/nyx144. PubMed PMID: 28379480.

980 92. Skoglund K, Enblad P, Marklund N. Monitoring and sedation differences in the management of 981 severe head injury and subarachnoid hemorrhage among neurocritical care centers. J Neurosci Nurs (2013) 45(6):360-8. Epub 2013/11/13. doi: 10.1097/JNN.0b013e3182a3cf4f. PubMed PMID: 24217146. 93. Flower O, Hellings S. Sedation in traumatic brain injury. Emerg Med Int (2012) 2012:637171. Epub 2012/10/11. doi: 10.1155/2012/637171. PubMed PMID: 23050154; PubMed Central PMCID: PMCPMC3461283.

988 94. Tanguy M, Seguin P, Laviolle B, Bleichner JP, Morandi X, Malledant Y. Cerebral microdialysis effects of propofol versus midazolam in severe traumatic brain injury. J Neurotrauma (2012) 29(6):110510. Epub 2011/12/21. doi: 10.1089/neu.2011.1817. PubMed PMID: 22182405. 
The Neurologic Wake-Up Test

95. Chiu WT, Lin TJ, Lin JW, Huang SJ, Chang CK, Chen HY. Multicenter evaluation of propofol for head-injured patients in Taiwan. Surg Neurol (2006) 66 Suppl 2:S37-42. Epub 2006/10/31. doi: 10.1016/j.surneu.2006.08.028. PubMed PMID: 17071254.

96. Hung YC, Lee EJ, Chen HY, Ko SW, Shyr MH, Chen TY. Effects of propofol sedation during the early postoperative period in hemorrhagic stroke patients. Acta Anaesthesiol Taiwan (2009) 47(3):12833. Epub 2009/09/19. doi: 10.1016/S1875-4597(09)60039-4. PubMed PMID: 19762303.

97. Otterspoor LC, Kalkman CJ, Cremer OL. Update on the propofol infusion syndrome in ICU management of patients with head injury. Curr Opin Anaesthesiol (2008) 21(5):544-51. Epub 2008/09/12. doi: 10.1097/ACO.0b013e32830f44fb. PubMed PMID: 18784477.

98. Song Y, Gao S, Tan W, Qiu Z, Zhou H, Zhao Y. Dexmedetomidine versus midazolam and propofol for sedation in critically ill patients: Mining the Medical Information Mart for Intensive Care data. Ann Transl Med (2019) 7(9):197. Epub 2019/06/18. doi: 10.21037/atm.2019.04.14. PubMed PMID: 31205915; PubMed Central PMCID: PMCPMC6545304.

99. McKenzie CA, McKinnon W, Naughton DP, Treacher D, Davies G, Phillips GJ, et al. Differentiating midazolam over-sedation from neurological damage in the intensive care unit. Crit Care (2005) 9(1):R326. Epub 2005/02/08. doi: 10.1186/cc3010. PubMed PMID: 15693964; PubMed Central PMCID: PMCPMC1065106.

100. Barr J, Fraser GL, Puntillo K, Ely EW, Gelinas C, Dasta JF, et al. Clinical practice guidelines for the management of pain, agitation, and delirium in adult patients in the intensive care unit. Crit Care Med (2013) 41(1):263-306. Epub 2012/12/28. doi: 10.1097/CCM.0b013e3182783b72. PubMed PMID: 23269131.

101. Paul BS, Paul G. Sedation in neurological intensive care unit. Ann Indian Acad Neurol (2013) 16(2):194-202. Epub 2013/08/21. doi: 10.4103/0972-2327.112465. PubMed PMID: 23956563; PubMed Central PMCID: PMCPMC3724073.

102. Khallaf M, Thabet AM, Ali M, Sharkawy E, Abdel-rehim S. The effect of dexmedetomidine versus propofol in traumatic brain injury: evaluation of some hemodynamic and intracranial pressure changes. Egyptian Journal of Neurosurgery (2019) 34(1):17. doi: 10.1186/s41984-019-0041-z.

103. Moreira FT, Serpa Neto A. Sedation in mechanically ventilated patients-time to stay awake? Ann Transl Med (2016) 4(19):382. Epub 2016/11/09. doi: 10.21037/atm.2016.09.37. PubMed PMID: 27826584 ; PubMed Central PMCID: PMCPMC5075853.

104. Wu J, Vogel T, Gao X, Lin B, Kulwin C, Chen J. Neuroprotective effect of dexmedetomidine in a murine model of traumatic brain injury. Sci Rep (2018) 8(1):4935. Epub 2018/03/23. doi: 10.1038/s41598-018-23003-3. PubMed PMID: 29563509; PubMed Central PMCID: PMCPMC5862953. 105. Kenney MJ, Larsen BT, McMurphy RM, Mason D, Fels RJ. Dexmedetomidine and regulation of splenic sympathetic nerve discharge. Auton Neurosci (2014) 183:111-5. Epub 2014/03/25. doi: 10.1016/j.autneu.2014.02.009. PubMed PMID: 24656574; PubMed Central PMCID: PMCPMC4058349. 106. M E. Dexmedetomidine in Traumatic Brain Injury, Why Not? Journal of Anesthesia \& Intensive Care Medicine (2017). Epub Feb 23, 2017. doi: 10.19080/JAICM.2017.01.555571.

107. Luo J HJ, He Y, Weng Q, Liu J, Yang M, Bian G, Liu T. Role of dexmedetomidine in stress control in traumatic brain injury and its influence on neuroendocrine system. Medical Journal of Chinese People's Liberation Army (2013). doi: 10.11855/j.issn.0577-7402.2013.11.011.

108. Humble SS, Wilson LD, Leath TC, Marshall MD, Sun DZ, Pandharipande PP, et al. ICU sedation with dexmedetomidine after severe traumatic brain injury. Brain Inj (2016) 30(10):1266-70. Epub 2016/07/28. doi: 10.1080/02699052.2016.1187289. PubMed PMID: 27458990; PubMed Central PMCID: PMCPMC5160042. 
1034

1035

1036

1037

1038

1039

1040

1041

1042

1043

1044

1045

1046

1047

1048

1049

1050

1051

1052

1053

1054

1055

1056

1057

1058

1059

1060

1061

1062

1063

1064
109. Devlin JW, Skrobik Y, Gelinas C, Needham DM, Slooter AJC, Pandharipande PP, et al. Clinical Practice Guidelines for the Prevention and Management of Pain, Agitation/Sedation, Delirium, Immobility, and Sleep Disruption in Adult Patients in the ICU. Crit Care Med (2018) 46(9):e825-e73. Epub 2018/08/17. doi: 10.1097/CCM.0000000000003299. PubMed PMID: 30113379.

110. Byrne MF. "Wake me up before you go-go". Drug, 'wham', scope, then snooze. Can't we do better with conscious sedation for endoscopy? Can J Gastroenterol (2006) 20(12):767-9. Epub 2006/12/16. doi: 10.1155/2006/670754. PubMed PMID: 17171194; PubMed Central PMCID: PMCPMC2660832.

111. Canbay O, Altiparmak B, Celebi N, Karagoz H, Saricaoglu F. Comparison of propofol and midazolam on patients undergoing spinal surgery with intraoperative wake-up test: randomized clinical trial. Braz J Anesthesiol (2015) 65(6):470-5. Epub 2015/11/29. doi: 10.1016/j.bjane.2013.10.003. PubMed PMID: 26614144.

112. Sandiumenge Camps A, Sanchez-Izquierdo Riera JA, Toral Vazquez D, Sa Borges M, Peinado Rodriguez J, Alted Lopez E. Midazolam and 2\% propofol in long-term sedation of traumatized critically ill patients: efficacy and safety comparison. Crit Care Med (2000) 28(11):3612-9. Epub 2000/12/01. doi: 10.1097/00003246-200011000-00009. PubMed PMID: 11098962.

113. Weinbroum AA, Halpern P, Rudick V, Sorkine P, Freedman M, Geller E. Midazolam versus propofol for long-term sedation in the ICU: a randomized prospective comparison. Intensive Care Med (1997) 23(12):1258-63. Epub 1998/02/21. doi: 10.1007/s001340050495. PubMed PMID: 9470082.

114. Fu X, Huang F, Chen Y, Deng Y, Wang Z. Application of dexmedetomidine-remifentanil in highintensity ultrasound ablation of uterine fibroids: a randomised study. BJOG (2017) 124 Suppl 3:23-9. Epub 2017/09/01. doi: 10.1111/1471-0528.14740. PubMed PMID: 28856857.

115. Tripathi M, Kumar V, Kalashetty MB, Malviya D, Bais PS, Sanjeev OP. Comparison of Dexmedetomidine and Midazolam for Sedation in Mechanically Ventilated Patients Guided by Bispectral Index and Sedation-Agitation Scale. Anesth Essays Res (2017) 11(4):828-33. Epub 2017/12/30. doi: 10.4103/aer.AER_48_17. PubMed PMID: 29284834; PubMed Central PMCID: PMCPMC5735473.

116. Hendrickson P, Pridgeon J, Temkin NR, Videtta W, Petroni G, Lujan S, et al. Development of a Severe Traumatic Brain Injury Consensus-Based Treatment Protocol Conference in Latin America. World Neurosurg (2018) 110:e952-e7. Epub 2017/12/06. doi: 10.1016/j.wneu.2017.11.142. PubMed PMID: 29203307; PubMed Central PMCID: PMCPMC6214355. 